\title{
LiNi 0.80 Co 0.15 Al 0.05 O2/LiCoO2 blends for high performance li-ion batteries
}

\author{
Muhammad Nur Ikhsanudin ${ }^{1}$, Setia Utaminingtyas ${ }^{1}$, Cornelius Satria Yudha ${ }^{1}$, Hendri Widiyandari ${ }^{2}$, \\ Agus Purwanto ${ }^{1 *}$ \\ ${ }^{1}$ Faculty of Engineering, Universitas Sebelas Maret, Surakarta, Indonesia \\ ${ }^{2}$ Faculty of Mathematics and Natural Science, Universitas Sebelas Maret, Surakarta, Indonesia \\ * Corresponding author: aguspurwanto@staff.uns.ac.id
}

\begin{abstract}
NCA (LiNi0.80Co0.15Al0.05O2) is one of the most promising Ni-rich cathode materials for lithium ion batteries. Ni-rich cathode materials have several advantages such as having high specific energy, high energy density, non-toxic, and relatively inexpensive manufacturing costs. The challenges of Ni-rich material are low capacity retention, difficult in preparation, and poor thermal stability. Several studies have shown that Co doping of Ni-rich material can increase the instability of the structure of $\mathrm{LiNiO} 2$ material layers and the presence of $\mathrm{Al}$ doping can increase the stability of its electrodes. Therefore, this study aims to increase the capacity of NCA batteries by blending NCA precursors with LCO (LiCoO2). NCA material synthesis used solid-state methods. All materials were mixed using mortar. LCO material was prepared by mixing $\mathrm{Co}(\mathrm{OH}) 2$ with $\mathrm{LiOH}$ with a molar ratio of $\mathrm{LiOH}: \mathrm{Co}(\mathrm{OH}) 2=1.05: 1$ using mortar. The samples were characterized using XRD and SEM. The electrochemical test is carried out in an 18650 cylindrical battery. Meso Carbon Micro Beads (MCMB) was used as the counter anode. The specific capacity of its sample was tested at a voltage of 2.7 to $4.25 \mathrm{~V}$ and the current of $1 / 10 \mathrm{C}$. The results show the most optimum LCO tuning ratio is NCA/LCO $=1: 1$ with a specific battery capacity of 122.165 $\mathrm{mAh} / \mathrm{g}$. As far as we are concern, there is no report published on investigating the LCO:NCA blending cathode characteristics and performance
\end{abstract}

Key words : li-ion battery, Ni-rich cathode materials, high performance battery, battery performance.

\section{INTRODUCTION}

The need for rechargeable lithium-ion batteries that have high-density energy is increasing along with the rapid development of technology. Electronic devices such as laptops, hand phone, even hybrid-car need a powerful energy source [1] [2]. Li-ion battery has several cathode materials such as LCO $\left(\mathrm{LiCoO}_{2}\right), \quad \mathrm{LMO} \quad\left(\mathrm{LiMn}_{2} \mathrm{O}_{4}\right), \quad \mathrm{NCA}$ $\left(\mathrm{LiNi}_{0.80} \mathrm{Co}_{0.15} \mathrm{Al}_{0.05} \mathrm{O}_{2}\right)$, and $\mathrm{LFP}\left(\mathrm{LiFePO}_{4}\right)$ [3].
The cathode material that is being developed is Ni-rich cathode. The advantages of nickel-based materials are having high specific energy, high energy density, non-toxic, and relatively inexpensive manufacturing costs [3]. The challenges of Ni-rich material are low capacity retention, difficult in preparation, and poor thermal stability. Several studies have shown that Co doping of Ni-rich material can increase the instability of the structure of $\mathrm{LiNiO}_{2}$ material layers and the presence of $\mathrm{Al}$ doping can increase the stability of its electrodes [1].

LCO ( $\mathrm{LiCoO} 2)$ as transitional metal oxide has been the first and the most commercially used as cathode materials for lithium secondary batteries due to high operating voltage, large diffusivity and easy to prepared [4]. However, LCO material gives several issue such as highly toxic, thermal instability, high cost manufacturing, poor rate ability that cause the capacity drop rapidly when used in hid current [5].

NCA (LiNi0.80Co0.15Al0.05O2) is one of the most promising Ni-rich cathode materials. Today, NCA is considered as a battery material for automobile application due to its strong advantages compared to other materials, i.e. low production cost, easy synthesis, ecofriendly, and has a high specific capacity [6]. The weakness of NCA material is chemical instability due to reductive tendency of $\mathrm{Ni}$ during its use which leads to irreversible capacity or capacity lost. NCA also has low thermal stability so that when charged at high currents its capacity will easily drop [7].

Several efforts were employed in order to enhance the performance of NCA, one of them is morphology control. However, morphology control required sophisticated apparatus which is inefficient to be applied for mass production. Coating of NCA is considered ineffective due to repeating process of heat treatments. On the other hand, Doping technique has been the effective and efficient since the doping process takes place during the NCA formation [8].

During this decade, several studies has been reported regarding the effect of atomic doping on NCA structure. Transitional metal such as $\mathrm{Mn}, \mathrm{Ti}, \mathrm{Fe}$ and $\mathrm{Y}$ has been 
successfully doped in NCA structure. Employing another type of metal as dopant will be a challenge since the properties of a dopant should enhance the NCA properties.

This research aims to increase the capacity of NCA batteries by doping NCA precursors with cobalt. In common NCA materials, Co atom can stabilize the structure of NCA resulting a stable performance both chemically and physically. There are several method for preparing cathode material for Lithium Ion (Li-ion) batteries, such as solid state method [9], Flame Assisted Spray Pyrolysis (FASP) [10], supercritical fluid synthesis [11], sol gel method [12], and hydrothermal method [6].

A solid state reaction was selected based on several factors : This method operates at a high temperature. The advantages of this method compared to the other synthesis methodology are can deal with large scale production [11], simple and cheap manufacturing [13], eco-friendly, high yield, and it does not need solvent [14].

The Co and NCA can also act as blending cathode which solve the drawbacks of LCO and NCA. The ratio of Co atom and $\mathrm{Ni}+\mathrm{Co}+\mathrm{Al}$ atom were varied to obtained LCO:NCA cathode. The samples were characterized using XRD and SEM. The electrochemical performance was employed in cylindrical cells. As far as we are concern, there is no report published on investigating the LCO:NCA blending cathode characteristics and performance.

The important of high performance battery is of important for future electric vehicle [15]. An example of process used batteries has been investigate [16].

\section{METHODOLOGY}

\subsection{Synthesis Process}

NCA material synthesis used solid-state methods like our previous report [5] [17]. The main ingredients are NCA-OH (Henan Cologne New Energy Co, Ltd) and LiOH ( Merck KGaA, 64271 Darmstadt, Germany, 98\% +). LiOH added to the mixture of previous materials with a molar ratio of $\mathrm{LiOH}$ : main ingredient $=1.05: 1$ All materials were mixed using mortar. LCO material was prepared by mixing $\mathrm{Co}(\mathrm{OH})_{2}$ with $\mathrm{LiOH}$ with a molar ratio of $\mathrm{LiOH}: \mathrm{Co}(\mathrm{OH})_{2}=1.05: 1$ using mortar.

\subsection{Material Test}

NCA material and LCO material were mixed in three variation ratio $\mathrm{wt} / \mathrm{wt}$. The variations are NCA:LCO $=1: 2$, NCA:LCO $=1: 1$, and NCA:LCO $=2: 1$. After all the materials mixed well, the next processes were calcination under atmospheric pressure at $550^{\circ} \mathrm{C}$ for 6 hours and continued with the sintering process under atmospheric conditions at $800^{\circ} \mathrm{C}$ for 12 hours. After sintering process, the material was manually finalized using mortar and sieve using 100 mesh SS-filters.

All sample materials were tested using XRD to analyze the crystal structure from each sample that employs $\mathrm{CuK \alpha}$ radiation $\lambda=1.54 \AA$ with a $2 \Theta$ range of $10-80^{\circ}$ and scan-rate of $0.02^{\circ}$ per second. Besides XRD, Scanning Electron Microscope (SEM) (JEOL JSM-6510LA, Japan) test is also carried out to observe the morphology of the NCA. The third test was an electrochemical test used to determine the performance of the batteries produced from each material. The electrochemical test was conducted in a 18650-type cylindrical full cell with NCA cathodes and graphite or mesocarbon mesobeads (MCMB) (MTI, America) as the anode with the voltage range of $2.7-4.25$ volts and $1 / 10 \mathrm{C}$ rate.

\subsection{Battery Manufacturing}

The battery has two electrodes: anode and cathode. The material synthesized in this research is cathode material. NCA / LCO material is the main material that functions as an active cathode sheet material. In addition to the main material used also other supporting materials including acetylene black $(\mathrm{AB})$ was used as a conductive agent, Polyvinyllidene Flouride (PVDF) was used as a binder, and N-methyl pyrrolidone (NMP) was used as an organic solvent [5].

Cylindrical battery type 18650 was used for electrochemical performance test with graphite as anode material. Graphite carbon as anode material has commercially used and still become a consideration for the anode material li-ion battery. The choice of graphite as anode material based on several advantages. Graphite shows good 2D mechanical stability, Li-ion transport, and has good electrical conductivity. Another advantages of graphite (carbon) are good abundant availability, perform high Li-ion transport, high electrical conductivity, graphite has low volume change due to lithiation/delithiation process, and low cost production [18].

The next step after synthesis the material is the fabrication of a positive electrode. First, mixed all the materials uniformly using a mortar and a pestle with the mass ratio of NCA: AB: $\mathrm{PVDF}=92: 3: 5$. The reason of selection mass basis for the mixture ratio are to ensure full $\mathrm{Li}$-ion transfer and the limiting electrode was cathode [5]. Put the mixture into dry oven for 30 minutes to remove the moisture content (water $/ \mathrm{H}_{2} \mathrm{O}$ ) because the solvent that used is organic solvent (NMP). Organic solvent is insoluble in water and the presence of water or moisture content in the mixture will break the slurry when NMC was added into the powder mixture, so the mixture is very sensitive with air. After 30 minutes in the dry oven, the mixture is added with NMP as organic solvent to made a homogeneous slurry. The slurry was coated on aluminum foil using doctor blade method with $200 \mu \mathrm{m}$ of thickness for each side and followed by drying process in an oven at $180^{\circ} \mathrm{C}$ for 45 minutes in wet oven. Before the battery 
manufacturing process, let the NCA cathode sheet at dry oven $65^{\circ} \mathrm{C}$. Pressed the cathode sheet using the rotary pressing machine then cut using slitting machine with the width 5.6 $\mathrm{cm}$ and the edge of cathode and anode were welded using $\mathrm{Ni}$ (for anode) and $\mathrm{Al}$ (for cathode) tab. The artificial graphite as anode and a cell-guard as separator were rolled with NCA cathode. The cell-guard separated anode and cathode to prevent contact between two electrodes. The tip of the cathode sheet welded to the cap of the cylindrical case and the tip of the anode sheet welded at the bottom. The electrolyte $(1 \mathrm{M}$ $\mathrm{LiPF}_{6}$ in Ethylene Carbonate (EC): Diethyl Carbonate (DEC):Dimethyl Carbonate $(\mathrm{DMC})=1: 1: 1, \mathrm{v} / \mathrm{v})$ was filled under Argon atmosphere using a glove box. Cylindrical full cell (18650) was tested using the electrochemical performance test at $2.7-4.25$ volt and $1 / 10 \mathrm{C}$ rate for charge-discharge analysis using an NEWARE Battery Analyzer and BTS software. The first 3 cycles were considered as formation process.

\section{RESULT AND DISCUSSION}

\subsection{XRD Test}

XRD (X-Ray Diffraction) test due to all sample NCA with tuning of LCO. This test analysis use $\mathrm{CuK} \alpha$ radiation in wavelength $1.5064 \AA$, and diffraction angle of $17-70^{\circ}$. Based on previous researches, NCA material has a layer of hexagonal structure that similar to $\alpha-\mathrm{NaFeO}_{2}$ belong to $\mathrm{R} \_3 \mathrm{~m}$ space group [3] [19]. The XRD patterns of NCA:LCO = 1:0.5 ; $1: 1 ; 0.5: 1$ will compare to XRD pattern of NCA and LCO to evaluate the tendency of the data. According to figure 1, all the samples has three main peaks of NCA at an angle range of $18-20^{\circ}, 36-38^{\circ}$, and $44-46^{\circ}$ The first peak layer contains a layer of oxygen, the second peak layer contains a layer of lithium, and the third peak layer contains a layer of Ni-Co-Al metal. Sharp peaks at an angle of $2 \Theta 17-19^{\circ}$ and $44-46^{\circ}$ show that NCA material has high crystalline properties [20]. However, from the XRD pattern shows with increasing of LCO ratio cause the sharpness of the three peaks decrease. Moreover, the more LCO ratio is added will effect the peak position displacement. The main peak will shift slightly to the right.

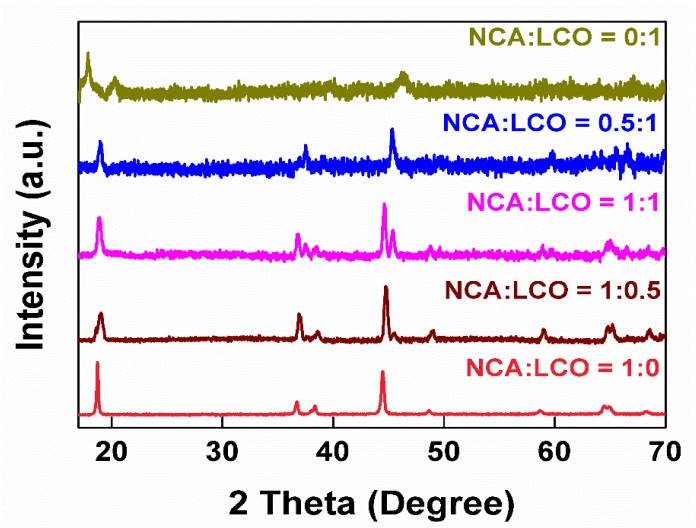

Figure 1: The XRD pattern of all samples
The presence of LCO material also affect the crystallinity of the material. Figure 1 shows more LCO added into the NCA material, the peak of XRD pattern will decrease. The XRD pattern also shows that more LCO added the noise formation will increase. The addition of LCO also affect the level of material maturity. The temperature in sintering process is $800^{\circ} \mathrm{C}$. LCO material will perfectly mature in the temperature above $900^{\circ} \mathrm{C}$. However, more LCO material is added into NCA, more material NCA/LCO that isn't yet perfectly cooked [5].

Besides the peak of the XRD pattern, crystallite size is also become a consideration in XRD analysis. The Debye- scherrer equation is used to calculate the crystallite size [17]. The Debye-scherrer equation was showed in Eq. (1).

$$
D p=\kappa \lambda / B \cos \theta
$$

The optimum size was the object for the crystallite calculation and the result of crystallite size calculation shows in Table 1.

Table 1: The result of crystalline size calculation.

\begin{tabular}{cc}
\hline Samples & $\begin{array}{c}\text { Crystallite Size } \\
(\mathrm{nm})\end{array}$ \\
\hline NCA:LCO $=1: 0$ & 24.1923 \\
NCA:LCO $=1: 0.5$ & 17.2887 \\
NCA $:$ LCO $=1: 1$ & 21.0877 \\
NCA:LCO $=0.5: 1$ & 14.2827 \\
NCA: $:$ CO $=0: 1$ & 12.0265 \\
\hline
\end{tabular}

Table 1 shows that sample with ratio NCA:LCO $=1: 0$ has the largest crystallite size. This is indicates that the sample has the best crystalline properties according to crystallite size (crystallite size $=27.1923 \mathrm{~nm}$ ). This result is align with the XRD pattern that NCA :LCO $=1: 0$ has the sharpest peak. The addition of LCO in NCA has good value of crystalline size at sample NCA $:$ LCO $=1: 1($ crystallite size $=21.0877 \mathrm{~nm})$.

The other samples show the value of crystalline size were below $20 \mathrm{~nm}$. Figure 2 below shows the trend for crystallite size.

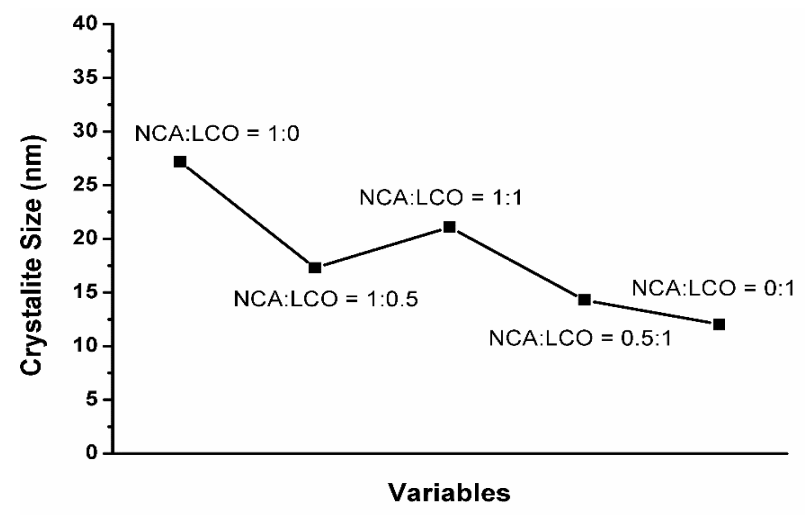

Figure 2: The trend graph of crystalline size 
Figure 2 concludes that the optimum ratio of NCA:LCO according to crystallite size is $1: 1$. The value of crystallite size is approach the value of NCA material (ratio NCA to LCO is 1:0). After ratio of NCA:LCO = 1:1, the value of crystallite size will decrease because higher ratio of LCO will cause agglomeration phenomenon and the solid- state reaction will not take place properly [21].

\subsection{SEM Test}

After synthesis process, the samples are also analyzed by SEM (Scanning Electron Microscope). Figure 3 and 4 show the result of SEM images of the sample which have passed the calcination process under atmospheric condition and high temperature $\left(800^{\circ} \mathrm{C}\right)$.

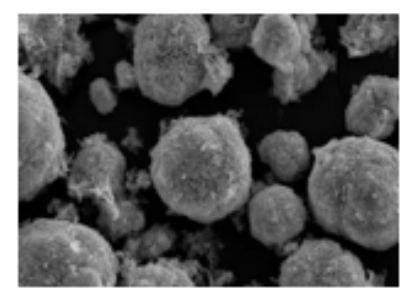

(a)

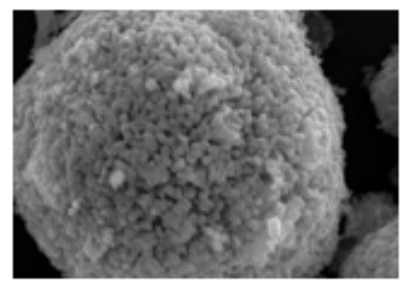

(d)

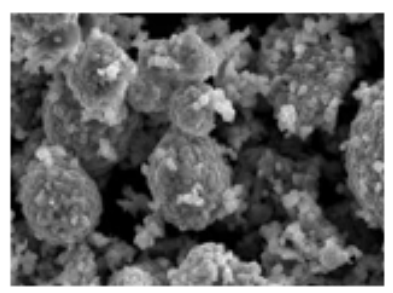

(c)

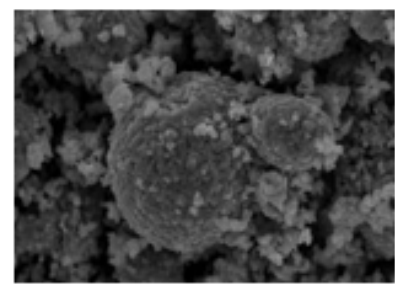

(b)

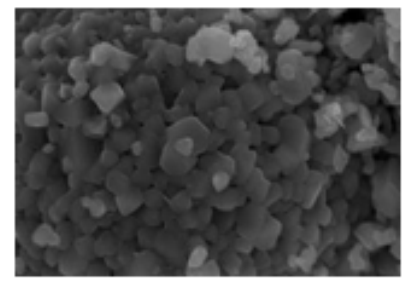

(e)

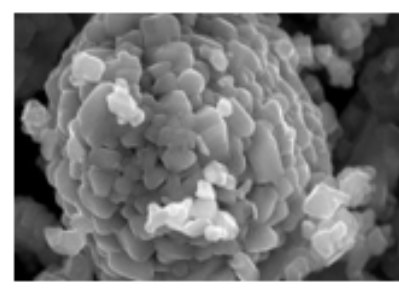

(f)
Figure 3: SEM analysis sample NCA/LCO

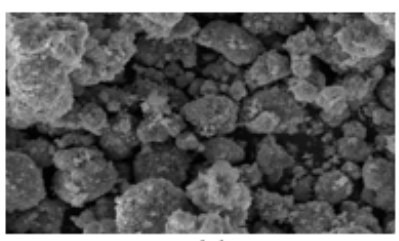

(c)

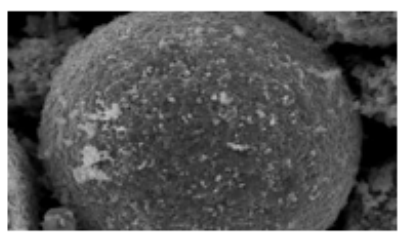

(c)

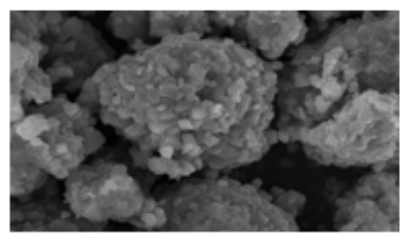

(b)

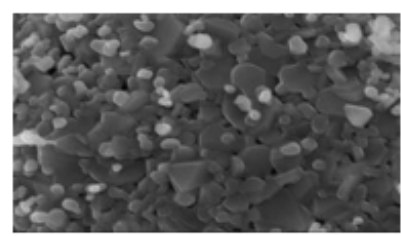

(d)
Figure 4: (a) and (b) are SEM analysis of NCA, (c) and (d) are SEM analysis of LCO
Figure 3 shows SEM images of the sample which have passed the calcination process. SEM analysis shows the morphology and size of the particle's diameter. Based on study by Nam et al. [22], to get high density and relatively large surface area, the spherical form is more desirable. Pictures $a, b, c$ are SEM images of $\mathrm{NCA} / \mathrm{LCO}=1: 1, \mathrm{NCA} / \mathrm{LCO}=0.5: 1$, and $\mathrm{NCA} / \mathrm{LCO}=1: 0.5$ samples with 3000x magnification respectively. Pictures d, e, f are SEM images of NCA/LCO = $1: 1, \mathrm{NCA} / \mathrm{LCO}=0.5: 1$, and NCA/LCO $=1: 0.5$ samples with 10000x magnification

There are 2 types of particles in the NCA samples namely primary particles and secondary particles. Primary particles show clearly in pictures $\mathrm{d}$, e, f while the secondary particles show in pictures a, b, c. Primary particles have a submicron size or less than 1 micron and the secondary particles are composed of submicron-sized primary particles [23].

The addition of cobalt in NCA material greatly influences the particle morphology. If the LCO composition value increases, the more aggregates are formed. Figure 4 (c) and (d) are SEM images of LCO samples with 3000x and 10000x magnification respectively. It shows that LCO material particles form aggregates but are easily destroyed. Figure (a) and (d) are SEM images of NCA samples with 3000x and 10000x magnification respectively. Figure a shows the morphology of a perfectly spherical NCA. The presence of LCO in NCA causes the empty space between NCA particles to be filled by LCO aggregates. The LCO aggregate can connect the free space between NCA particles so that the electron transfer will be better. This is because the distance between the NCA particles becomes increasingly narrow.

The average diameter size of the primary particle and secondary particle are presented in Table 2 .

Table 2: Analysis of particle size

\begin{tabular}{l|c|c|c|c|c}
\hline \multirow{2}{*}{$\begin{array}{l}\text { Particle } \\
\text { size } \\
\text { analysis }\end{array}$} & \multicolumn{5}{|c}{ Value } \\
\cline { 2 - 6 } & $\begin{array}{l}\text { NCA/ } \\
\text { LCO } \\
1: 1\end{array}$ & $\begin{array}{c}\text { NCA/ } \\
\text { LCO } \\
=0.5: 1\end{array}$ & $\begin{array}{c}\text { NCA/ } \\
\text { LCO } \\
=1: 0.5\end{array}$ & NCA & LCO \\
\hline $\begin{array}{l}\text { Primary } \\
\text { particle } \\
(\mu \mathrm{m})\end{array}$ & 0.4031 & 0.7364 & 0.7597 & 0.7519 & 0.7132 \\
$\begin{array}{l}\text { Secondary } \\
\text { particle } \\
(\mu \mathrm{m})\end{array}$ & 7.9845 & 7.2480 & 6.8992 & 4.4186 & 33.0232 \\
\hline
\end{tabular}

\subsection{Electrochemical Performance Test}

In this test using the NCA/LCO-Graphite system. NCA/LCO as a cathode and graphite as an anode material. The choice of graphite as an anode material because graphite is cheaper than Li-metal, has a high theoretical specific capacity, and has been widely used in the manufacture of commercial 
batteries [18]. Electrochemical performance tests are carried out in the form of 18650 cylindrical batteries. Li-ion batteries are tested with a current capacity of $1 / 10 \mathrm{C}$ and a voltage range of 2.7-4.25 volts.

This test is carried out on all variations of the LCO tuning of the NCA which is also compared with batteries that use only NCA materials and those that use only LCO materials. The following are the results of battery capacity testing as indicated by the charge/discharge curve in Figure 5 .

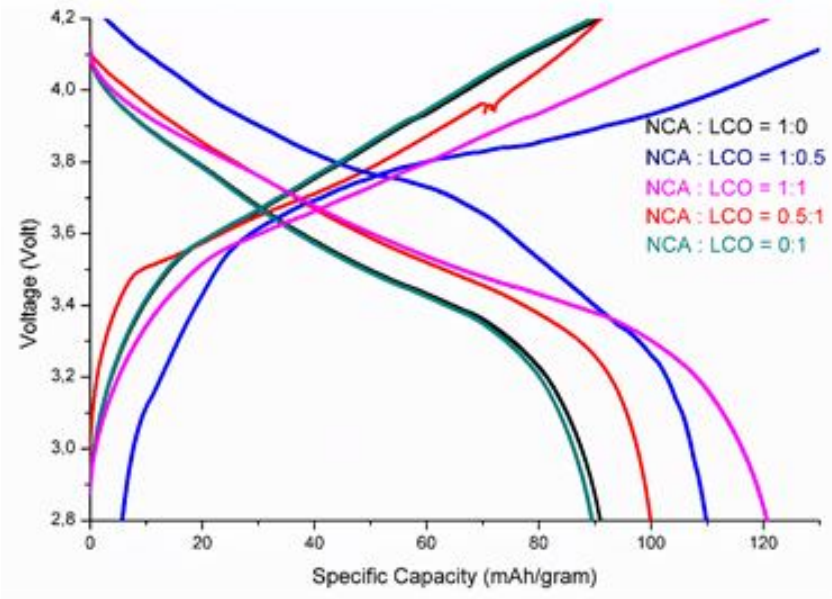

(a)

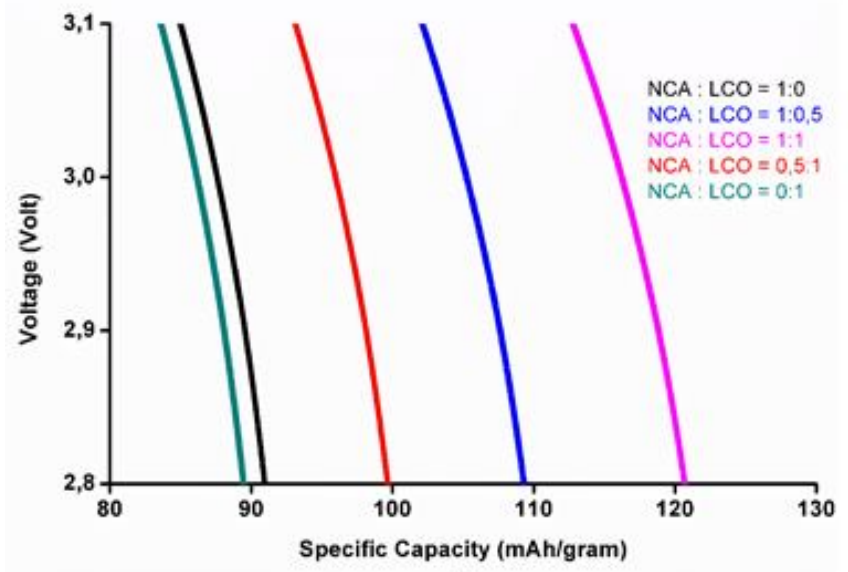

(b)

Figure 5: (a) The charge/discharge specific capacity curve of all samples. ; (b) Zoomed charge/discharge curve.

Electrochemical performance test results on all samples can be seen in Table 3 .

Table 3: Electrochemical performance test for all samples

\begin{tabular}{llc}
\hline No. & Samples & $\begin{array}{c}\text { Specific Capacity } \\
(\mathrm{mAh} / \mathrm{g})\end{array}$ \\
\hline 1 & NCA:LCO $=1: 0$ & 90.516 \\
2 & NCA:LCO $=1: 0.5$ & 110.631 \\
3 & NCA:LCO $=1: 1$ & 122.165 \\
4 & NCA:LCO $=0.5: 1$ & 100.861 \\
5 & NCA:LCO $=0: 1$ & 92.059 \\
\hline
\end{tabular}

Based on the specific capacity Table 3 produced by all variations, the most optimum LCO tuning ratio is NCA / LCO $=1: 1$ with a specific battery capacity of $122.165 \mathrm{mAh} / \mathrm{g}$.

In the charging process, the reaction that occurs is that $\mathrm{Li}$ ions are intercalated from the structure of the cathode active material (NCA / LCO) to the electrolyte and move to graphite material. The transfer process is followed by the oxidation process of $\mathrm{Ni}^{3+}$ metal ions to $\mathrm{Ni}^{4+}$ ions. While the reverse process occurs in the discharging process, from the graphite material to the electrolyte and then moves to the cathode material (NCA / LCO).

\section{CONCLUSION}

Synthesis of $\mathrm{LiNi}_{0.85} \mathrm{Co}_{0.14} \mathrm{Al}_{0.01} \mathrm{O}_{2}$ cathode material was performed via solid-state using mortar. Co doping of Ni-rich material increase the instability of the structure of $\mathrm{LiNiO}_{2}$ material layers and increase the stability of its electrodes. The purpose of this research is to increase the characteristic properties and capacity of NCA batteries by blending NCA precursors with $\mathrm{LCO}\left(\mathrm{LiCoO}_{2}\right)$. Based on XRD patterns analysis, the of LCO added to NCA material are affect the shift of three main peaks and the noise formation along the XRD pattern. From the crystallite size calculation we can conclude that the optimum ratio of NCA:LCO according to crystallite size is $1: 1(21.0877 \mathrm{~nm})$. The value of crystallite size is approach the ideal value of NCA material with ratio NCA to LCO is 1:0 $(24.1933 \mathrm{~nm})$. The SEM analysis prove that the presence of LCO in NCA will site the void volume between NCA molecules and it makes the electron transfer better. The electrochemical test showed that the initial discharge capacity of the most optimum LCO tuning ratio $(\mathrm{NCA} / \mathrm{LCO}=1: 1)$ is $122.165 \mathrm{mAh} / \mathrm{g}$. According to the all three test that applied to all variables, the most optimum ratio of NCA/LCO is $1: 1$.

\section{ACKNOWLEDGEMENT}

This research was funded by LPDP through the RISPRO Invitation Scheme (Contract number: PRJ-31/LPDP/2018) and the Ministry of Research, Technology and Higher Education (KemenRistekdikti) through the Penelitian Hibah Kompetensi (Contract number: 474/UN27.21/PP/2018).

\section{REFERENCES}

1. He, K., Ruan, Z., Teng, X., \& Zhu, Y. (2017). Facile synthesis and electrochemical properties of spherical LiNi0.85- xCo0.15AlxO2 with sodium aluminate via co-precipitation. Materials Research Bulletin, 90, 131-137. https://doi.org/10.1016/j.materresbull.2017.01.039

2. Diah, K., Ekawati, R., \& Maret, U. S. (2018). Comparative Study of NCA Cathode Material Synthesis 
Methods towards Their Structure Characteristics. 2018 5th International Conference on Electric Vehicular Technology (ICEVT), 57-61.

3. Qiu, Z., Zhang, Y., Xia, S., \& Yao, Y. (2017). A facile method for synthesis of LiNi0.80Co0.15Al0.05O2 cathode material. Solid State Ionics, 307(May), 73-78. https://doi.org/10.1016/j.ssi.2017.04.011

4. Yong, E., Mumm, D. R., Ryoung, H., \& Youp, M. (2012). Lithium nickel cobalt oxides synthesized from $\mathrm{Li} 2 \mathrm{CO} 3, \mathrm{NiO}$ and $\mathrm{Co} 3 \mathrm{O} 4$ by the solid-state reaction method. Ceramics International, 38(5), 3635-3641. https://doi.org/10.1016/j.ceramint.2012.01.002

5. Yudha, C. S., Muzayanha, S. U., Widiyandari, H., Iskandar, F., Sutopo, W., \& Purwanto, A. (2019). Synthesis of LiNi0.85Co0.14Al0.01O2 Cathode Material and its Performance in an NCA/Graphite Full-Battery. MDPI.

6. Zhang, L., Dong, T., Yu, X., Dong, Y., Zhao, Z., \& Li, H. (2012). Synthesis and electrochemical performance of LiNi0.7Co0.15Mn0.15O2 as gradient cathode material for lithium batteries. Materials Research Bulletin, $47(11)$, 3269-3272. https://doi.org/10.1016/j.materresbull.2012.08.002

7. Dai, G., Du, H., Wang, S., Cao, J., Yu, M., \& Chen, Y. (2016). Improved electrochemical performance of LiNi0.8Co0.15Al0.05O2 with ultrathin and thickness controlled $\mathrm{TiO} 2$ shell via atomic layer deposition technology. 20, 100841-100848.

https://doi.org/10.1039/C6RA21903A

8. Purwanto, A., Yudha, C. S., Ubaidillah, U., Widiyandari, H., Ogi, T., \& Haerudin, H. (2018). NCA cathode material: Synthesis methods and performance enhancement efforts. Materials Research Express, 5(12), 122001. https://doi.org/10.1088/2053-1591/aae167

9. Xia, Y., Wierzbicki, T., Sahraei, E., \& Zhang, X. (2014). Damage of cells and battery packs due to ground impact. Journal of Power Sources, 267, 78-97. https://doi.org/10.1016/j.jpowsour.2014.05.078

10. Suryono. (2015). Fabrikasi Lithium Iron Phosphate Carbon Sebagai Material Katoda Baterai Lithium Ion. Sebelas Maret.

11. Uddin, M., Alaboina, P. K., \& Cho, S. (2017). Nanostructured cathode materials synthesis for lithium-ion batteries. Materials Today Energy, 5, 138-157. https://doi.org/10.1016/j.mtener.2017.06.008

12. Joo, C., Hyuk, J., Il, W., \& Jang, H. (2004). Electrochemical properties of $\mathrm{LiNi0} .8 \mathrm{Co} 0.2-\mathrm{xAlxO} 2$ prepared by a sol-gel method. 136, 132-138. https://doi.org/10.1016/j.jpowsour.2004.05.006

13. Tanabe, T., Gunji, T., Honma, Y., Miyamoto, K., Tsuda, T., \& Matsumoto, F. (2017). Electrochimica Acta Preparation of Water-Resistant Surface Coated High-Voltage LiNi0.5Mn1.5O4 Cathode and Its Cathode Performance to Apply a Water-Based Hybrid Polymer Binder to Li-Ion Batteries. Electrochimica Acta, 224, 429-438.

https://doi.org/10.1016/j.electacta.2016.12.064
14. Xinrong, D., Guorong, H. U., Zhongdong, P., Yanan, Y., Yanbing, C. A. O., \& Ke, D. U. (2008). Preparation and electrochemical characteristics of $\mathrm{Co} 3(\mathrm{PO} 4) 2$-coated $\mathrm{LiNi} 0.8 \mathrm{Co} 0.2 \mathrm{O} 2$ by solid-state reaction at room temperature. Rare Metals, 27(5), 502-506. https://doi.org/10.1016/S1001-0521(08)60170-9

15. Kulikov, I., Karpukhin, K. (2020). Studying energy efficiency of thermal management systems designed for electric vehicles with in-wheel motors, International Journal of Emerging Trends in Engineering Research, 8(6), 2654-2662. https://doi.org/10.30534/ijeter/2020/71862020

16. Tjahjanti, P.H., Firdaus, R., Iswanto, Nurcahyo, R., Ariyani, S., N.f.ganda, A. (2020). Utilization of graphite bars on used batteries become coating material for steel, International Journal of Emerging Trends in Engineering Research, 8(6), 2481-2485. https://doi.org/10.30534/ijeter/2020/44862020

17. Muzayanha, S. U., Yudha, C. S., Nur, A., Widiyandari, H., Haerudin, H., Nilasary, H., Purwanto, A. (2019). A Fast Metals Recovery Method for the Synthesis of Lithium Nickel Cobalt Aluminum Oxide Material from Cathode Waste Soraya. MDPI.

18. Nitta, N., Wu, F., Lee, J. T., \& Yushin, G. (2015). Li-ion battery materials: present and future. Biochemical Pharmacology, 18(5), 252-264. https://doi.org/10.1016/j.mattod.2014.10.040

19. Xia, S., Zhang, Y., Dong, P., \& Zhang, Y. (2014). Synthesis cathode material LiNi0.80Co0.15Al0.05O2 with two step solid- state method under air stream. The European Physical Journal Applied Physics, 1-6. https://doi.org/10.1051/epjap/2013130328

20. Hsieh, C., Hsu, H., Hsu, J., Chen, Y., \& Chang, J. (2016). Infrared-assisted Synthesis of Lithium Nickel Cobalt Alumina Oxide Powders as Electrode Material for Lithium-ion Batteries. Electrochimica Acta, 206, 207-216. https://doi.org/10.1016/j.electacta.2016.04.146

21. Javanbakht, M., Izadyar, M., \& Omidvar, H. (2018). Synthesis And Electrochemical Performance Of Copper-Doped Lini0.8co0.15al0.05o2 For Application In Lithium-Ion Batteries. International. Journal of Advances in Science Engineering and Technology, (2), 27-31.

22. Nam, K. W., Yoon, W. S., \& Yang, X. Q. (2009). Structural changes and thermal stability of charged LiNi1/3Co1/3Mn1/3O2 cathode material for Li-ion batteries studied by time-resolved XRD. Journal of Power Sources, $\quad 189(1)$, 515-518. https://doi.org/10.1016/j.jpowsour.2008.10.130

23. Hwang, I., Lee, C. W., Kim, J. C., \& Yoon, S. (2012). Particle size effect of Ni-rich cathode materials on lithium ion battery performance. Materials Research Bulletin, 47(1), 73-78. https://doi.org/10.1016/j.materresbull.2011.10.002 